\title{
Optimal control of combined sewer systems using SWMM 5.0
}

\author{
U. S. Rathnayake \& T. T. Tanyimboh \\ Department of Civil Engineering, University of Strathclyde, Glasgow, UK
}

\begin{abstract}
Combined sewer networks carry wastewater and stormwater together. Capacity limitation of these sewer networks results in combined sewer overflows (CSOs) during high-intensity storms. Untreated CSOs when directly discharged to the nearby natural water bodies cause many environmental problems. Controlling urban wastewater systems is one possible way of addressing the environmental issues from CSOs. However, controlling urban sewer systems optimally is still a challenge, when considering the receiving water quality effects. In this study, a multi-objective optimization approach was formulated considering the pollution load to the receiving water from CSOs and the cost of the wastewater treatment. The optimization model was tested using an interceptor sewer system. The results demonstrate the benefits of the multi-objective optimization approach and its potential to establish the key properties of a range of control strategies through an analysis of the various tradeoffs involved.

Keywords: combined sewer overflows, effluent quality index, evolutionary computing, genetic algorithm, multi-objective optimization, combined sewer systems.
\end{abstract}

\section{Introduction}

Combined sewer networks carry dry weather flow (DWF) and stormwater together. Capacity limitation of these sewer networks results in combined sewer overflows (CSOs) during high-intensity storms. Untreated CSOs when directly discharged to the nearby natural water bodies cause many environmental problems. Controlling existing urban sewer networks is one possible way of addressing the issues in urban wastewater systems. However, it is still a challenge, when considering the receiving water quality effects. 
Most of the literature on controlling combined sewer systems is based on volumetric measures [1-3]. These include the optimal storage controls to utilize the temporary storage in sewer networks to provide more detention time. However, they failed to address the issue of water quality in both combined sewers and receiving waters. In addition, economic measures, such as treatment cost at downstream wastewater treatment plant, in general are not considered. Furthermore, most of the previous work was based on simplified hydraulic models [4]. Complexity of the problem is the main issue in developing a holistic approach.

However, Rathnayake and Tanyimboh [5] have proposed a multi-objective optimization approach in controlling urban wastewater systems based on receiving water quality due to $\mathrm{CSO}$ and the wastewater treatment cost. More importantly that approach considers the results from full hydraulic simulations.

This paper presents an improvement to the multi-objective optimization approach discussed in Rathnayake and Tanyimboh [5]. Deb's binary tournament selection technique [6] was used to handle the constraints in Rathnayake and Tanyimboh [5], whereas a different constraint handling technique was used to handle the constraints in this paper. A detailed explanation about this constraint handling technique can be found in section 5 .

A multi-objective optimization approach was developed, considering the pollution load to the receiving water from CSOs and the wastewater treatment cost. Simulation results from a full hydraulic model, including water quality routing were used in the optimization. The performance of the multi-objective optimization model was tested on a simple interceptor sewer system. Results from full hydraulic simulations were presented for different optimal controlling settings.

\section{Pollution load evaluation}

Effluent quality index (EQI) is formulated to calculate the pollution load in a water body as a single variable. Five important water quality parameters, total suspended solids (TSS), chemical oxygen demand (COD), five-day biochemical oxygen demand $(B O D)$, total Kjeldahl nitrogen $(T K N)$ and nitrates/nitrites $(N O X)$ are accumulated together in forming this single measure. A detailed explanation of this EQI can be found in Mussati et al. [7] and Rathnayake and Tanyimboh [8].

\section{Wastewater treatment cost}

It is common practice to have a treatment plant with an overall capacity of $6 \times \mathrm{DWF}$. However, the full treatment capacity is further limited to $3 \times \mathrm{DWF}$ and the surplus flow is temporarily stored in equalization tanks which have the same role as primary sedimentation tanks. In a case where the total flow is more than $6 \times \mathrm{DWF}$, the storm tanks fill completely and overflow to nearby natural water. Based on various cost models from literature, a generic cost function based on 
the treated water volume was adopted. The treatment cost, $C_{T}$ (€/year) is described as

$$
C_{T}=\left\{\begin{array}{cc}
A \times q_{T}^{0.659}, & q_{T} \leq 3 \times D W F \\
B+\frac{2}{3} C, \quad 3 \times D W F \leq q_{T} \leq 6 \times D W F \\
B+\frac{2}{3} D, \quad q_{T}>6 \times D W F
\end{array}\right.
$$

where

$$
\begin{gathered}
A=916.862 \times 86400^{0.659} \\
B=916.862 \times(3 \times D W F)^{0.659} \\
C=1.69 \times\left(q_{T}-3 \times D W F\right)+11376 \\
D=(1.69 \times 3 \times D W F)+11376
\end{gathered}
$$

where $q_{T}\left(\mathrm{~m}^{3} / \mathrm{s}\right)$ is the treated wastewater volume flow rate.

Total treatment cost, including personnel, energy, maintenance, waste and other costs, when the wastewater flow rate is less than or equal to $3 \times \mathrm{DWF}$ is given by Hernandez-Sancho et al. [9]. However, the additional cost, including storage cost, should be included, when the flow rate is more than $3 \times \mathrm{DWF}$. Eqns. (1b and 1c) give the wastewater treatment cost at the treatment plant and the operational and maintenance cost for storage tanks when the flow rate is in between $3 \times$ DWF and $6 \times$ DWF and when more than $6 \times$ DWF respectively. More details on the development of Eqn. (1) can be found in Rathnayake and Tanyimboh [5].

\section{Problem formulation and solution}

Typical configurations for an interceptor sewer and a CSO chamber are shown in the Figure 1. The first objective function was formulated to minimize the pollution load to receiving water through the CSOs. EQI, which gives the pollution load, was used to formulate this objective function.

$$
\text { Minimize } F_{1}=\sum_{i=1}^{n} P_{i}
$$

where $n$ and $P_{i}$ are the number of interceptor nodes or CSO chamber points and the pollution load to the receiving water from the $i^{\text {th }}$ CSO chamber respectively.

The second objective function was formulated to minimize the wastewater treatment cost at downstream treatment plant.

$$
\text { Minimize } F_{2}=C_{T}
$$


where $C_{T}$ is the treatment cost at the wastewater treatment plant. Referring to Figure 1 , the continuity equations are described as

$$
\begin{gathered}
Q_{i}+q_{i-1}-q_{i}=0 \\
A_{C} \frac{\Delta h_{C}}{\Delta t}=I_{i}-Q_{i} \quad ; h_{C}<h_{S} \\
A_{C} \frac{\Delta h_{C}}{\Delta t}=I_{i}-Q_{i}-O_{i} ; \quad h_{C}>h_{s} \\
0 \leq q_{i} \leq q_{\text {max }, i}
\end{gathered}
$$

where $A_{C}$ is the surface area of the CSO chamber and $q_{\text {max }, i}$ is the maximum flow rate at $i^{\text {th }}$ conduit.
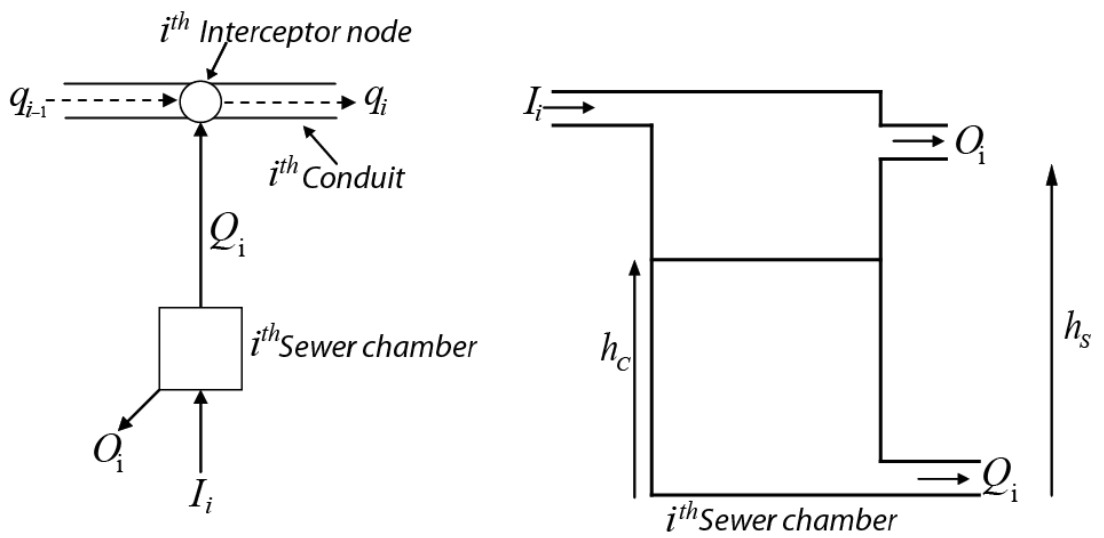

$I_{i}-$ Catchment inflow to node $i$

$Q_{i}-$ Flow from $i^{\text {th }}$ sewer chamber to interceptor node $i$

$q_{i}$ - Through flow in interceptor sewer at node $i$

$O_{i}$ - Combined sewer over flow discharge at node $i$

$h_{C}-$ Water level in sewer chamber

$h_{S}-$ Spill level of sewer chamber

Figure 1: $\quad$ Schematic diagram of sewer chamber.

\section{Solution to the multi-objective optimization approach}

The hydraulic model, U.S. EPA SWMM 5.0 [10] and the multi-objective optimization module, NSGA II [6] were coupled using " $\mathrm{C}$ " programming language. NSGA II has already been successfully applied to many practical optimization problems in various disciplines. SWMM 5.0 is a dynamic rainfallrunoff simulation model and is primarily used to simulate urban and sub-urban areas.

It is assumed here that wastewater flow from CSO chamber to the interceptor sewer is controlled using an orifice at the bottom of the CSO chamber. Orifice openings were initially generated randomly. Hence, the decision variables $\left(q_{i}\right)$ of 
the optimization approach were indirectly generated. Next, a full hydraulic simulation, including water quality routing was carried out using SWMM 5.0 the results of which were used to calculate the pollution load $F_{1}$ and the wastewater treatment cost $F_{2}$.

Mass balance and conservation of energy were automatically satisfied by the hydraulic model. Maximum flow rates allowed through conduits were formulated inside the hydraulic model. SWMM 5.0 conduit features in defining the maximum flow rates were used in formulating the maximum flow rates allowed through conduits as shown in the Eqn. (11). By contrast, Deb's binary tournament selection technique was used to handle constraints in Rathnayake and Tanyimboh [5]. The maximum flow rates allowed through conduits were externally satisfied by this constraint handling approach. A detailed explanation about Deb's constraint handling technique can be found in Deb et al. [6] and Rathnayake and Tanyimboh [5].

\section{Case study}

The developed multi-objective optimization model was applied to a simplified interceptor system. A description of this interceptor sewer system can be found in Thomas [11]. The interceptor sewer system was modified, for this study. The CSO chambers $T 1$ to $T 7$ are described in Thomas [11]. Two storage tanks (T8 and T9) were introduced at upper catchments of Strand Rd. and Northern. Figure 2 shows the modified interceptor sewer system. Maximum flow rates allowed through $C 1, C 2$ and $C 3$ are $3.26 \mathrm{~m}^{3} / \mathrm{s}$ and that of $C 4, C 5, C 6$ and $C 7$ are $7.72 \mathrm{~m}^{3} / \mathrm{s}$. The diameter for $C 1$ to $C 3$ is $1.66 \mathrm{~m}$ and that of $C 4$ to $C 7$ is $2.44 \mathrm{~m}$. Depths of the CSO chambers ( $T 1$ to $T 7$ ) and storage tanks ( $T 8$ and $T 9$ ) are 6.42, $7.91,8.95,9.04,9.18,9.47,10.26,8.00$ and $9.00 \mathrm{~m}$ respectively. Storage tanks $T 8$ and $T 9$ are generic and the details of the flow control in these tanks are not discussed in this paper.

Diurnal effects of the DWF were not considered in this study. Therefore, average flow rates of DWFs were fed to the T1, T3, T4, T6, T7 CSO chambers and T8, T9 storage tanks. More details on the storm run-off flow hydrographs can be found in Thomas [11]. Five different land-uses, including residential, industrial, commercial, agricultural and mid urban were assumed when generating the pollutographs for five different water quality constituents [12]. Shapes of the pollutographs of five different water constituents (TSS, COD, $B O D, N O X$, and $T K N$ ) were reviewed from the literature [13-16]. More details of these pollutographs can be found in Rathnayake and Tanyimboh [8].

A basic real-coded NSGA II program was used in this study. The optimization process was done with a population of 100, 100 generations and a crossover probability of 1 . The simulated binary crossover uses a probability distribution around two parents to create two children solutions [17]. The distribution indices for crossover and mutation operators were kept at 20 [6]. The distribution indices for crossover and mutation are parameters that define the shape of the probability distribution for the simulated binary crossover and polynomial mutation respectively [17]. 


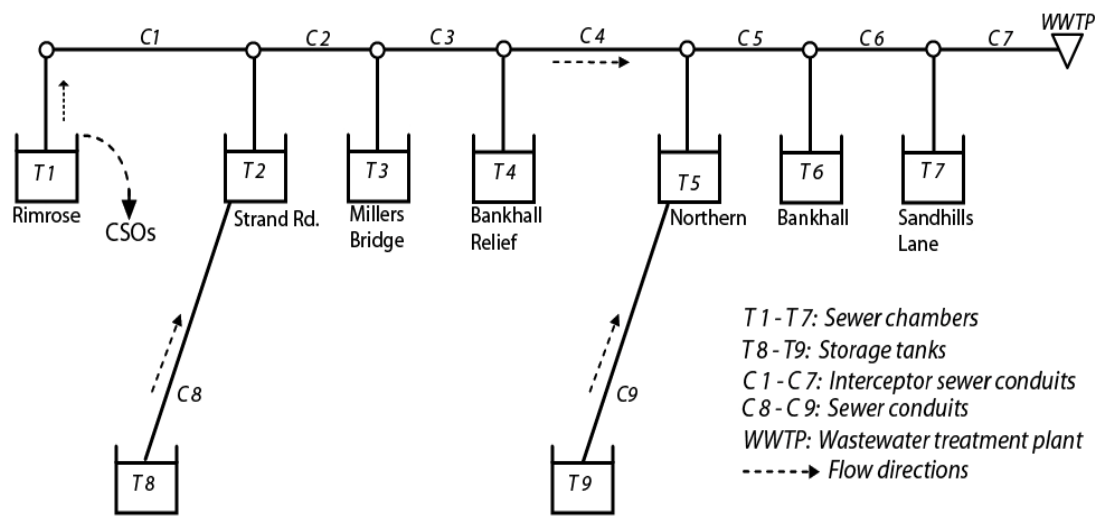

Figure 2: Interceptor sewer system.

Many optimization runs with different random seeds were conducted. Different mutation probabilities were tried in different runs. The reason for selecting different mutation probabilities was to compare the performance of the mutation probabilities for this optimization problem. Polynomial mutation, described in Deb et al. [6], was used for this optimization approach. The polynomial mutation operator creates a new value for the decision variable, which is near the vicinity of the original value using a probability distribution.

Routing time-step in SWMM 5.0 was kept at 30 seconds, and the results were obtained at 15 minutes. Then, the NSGA II optimization module was run using the obtained results. Each GA run took about 9 minutes on a Pentium 4 desktop personal computer with a Core 2 Duo processor and 4 GB of RAM.

\section{Results and discussion}

The best Pareto optimal front was achieved with a mutation probability of 0.4 over the entire population of solutions, i.e. when $40 \%$ of randomly selected decision variables from the whole population were muted. Pareto optimal front for 0.4 mutation rate is shown in Figure 3.

Solutions A to H (Figure 3) were selected for further assessment. Results from full hydraulic simulations for these solutions are presented in the following tables.

As stated above, the flow rates through the conduits of the interceptor sewer were constrained. It can be clearly seen in Table 1 that the flow rates through these conduits are less than or equal to the maximum allowed flow rate for all the tabulated cases. Furthermore, Table 2 shows the CSO rates for Solutions A to $\mathrm{H}$. Solution A that corresponds to the minimum pollution load to receiving water has smaller CSO rates than Solution $\mathrm{H}$ that corresponds to the minimum wastewater treatment cost. Table 3 shows the pollution load to the receiving water from CSO chambers and the storage tanks for Solutions A to H. Solution A has the minimum pollution load to the receiving water, whereas Solution $\mathrm{H}$ 


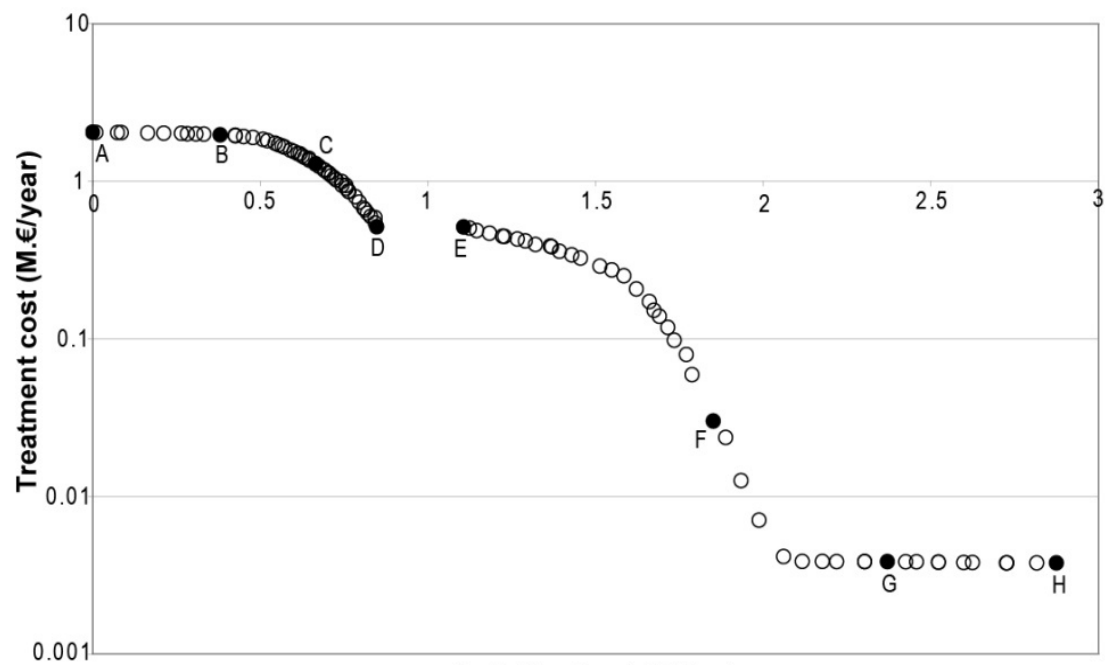

Pollution load (kt/day)

Figure 3: $\quad$ Best Pareto optimal front achieved.

Table 1: Flow rates through the interceptor sewer sections at $\mathrm{t}=15$ minutes.

\begin{tabular}{|c|c|c|c|c|c|c|c|}
\hline \multirow{2}{*}{ Solution } & \multicolumn{7}{|c|}{ Interceptor sewer flow rates $\left(\mathrm{m}^{3} / \mathrm{s}\right)$} \\
\cline { 2 - 8 } & $C 1$ & $C 2$ & $C 3$ & $C 4$ & $C 5$ & $C 6$ & $C 7$ \\
\hline A & 2.70 & 1.61 & 3.26 & 5.37 & 4.57 & 2.67 & 1.40 \\
\hline B & 2.70 & 1.61 & 3.26 & 5.01 & 4.45 & 2.56 & 1.32 \\
\hline C & 2.69 & 1.60 & 3.26 & 4.16 & 3.74 & 1.86 & 0.69 \\
\hline D & 2.70 & 1.60 & 3.26 & 3.19 & 2.73 & 0.91 & 0.17 \\
\hline E & 2.70 & 1.60 & 3.26 & 3.14 & 2.71 & 0.89 & 0.17 \\
\hline F & 2.70 & 1.55 & 1.78 & 1.62 & 0.87 & 0.10 & 0 \\
\hline G & 2.50 & 1.46 & 0.43 & 0.12 & 0 & 0 & 0 \\
\hline H & 0.03 & 0 & 0 & 0 & 0 & 0 & 0 \\
\hline
\end{tabular}

has the maximum pollution load. Table 4 shows the wastewater depths at CSO chambers and storage tanks for Solutions A to H. It can be seen in Table 4 that the storage tanks ( $T 8$ and $T 9$ ) store wastewater in order to prevent CSOs at downstream $T 2$ and $T 5$ CSO chambers.

In comparison with the results presented in Rathnayake and Tanyimboh [5], the results obtained here show a better optimal control of urban wastewater systems. Solution A that corresponds to the minimum pollution load to receiving water gives $0 \mathrm{kt} /$ day pollution load whereas it is $5.57 \mathrm{kt} /$ day in Rathnayake and Tanyimboh [5]. Similarly Solution H corresponds to the minimum wastewater treatment cost gives $3776 €$ /year cost whereas it is $3859 € /$ year in Rathnayake and Tanyimboh [5]. 
Table 2: Combined sewer overflow rates at CSO chambers at $\mathrm{t}=15$ minutes.

\begin{tabular}{|c|c|c|c|c|c|c|c|c|c|}
\hline & \multicolumn{10}{|c|}{ Combined sewer overflows $\left(\mathrm{m}^{3} / \mathrm{s}\right)$} \\
\cline { 2 - 11 } Solution & $T 1$ & $T 2$ & $T 3$ & $T 4$ & $T 5$ & $T 6$ & $T 7$ & $T 8$ & $T 9$ \\
\hline A & 0 & 0 & 0 & 0 & 0 & 0 & 0 & 0 & 0 \\
\hline B & 0 & 0 & 0.01 & 1.84 & 0 & 0 & 0 & 0 & 0 \\
\hline C & 0 & 0 & 0.01 & 3.34 & 0 & 0 & 0 & 0 & 0 \\
\hline D & 0 & 0 & 0 & 4.36 & 0 & 0 & 0 & 0 & 0 \\
\hline E & 0 & 0 & 0.97 & 4.35 & 0 & 0 & 0 & 0 & 0 \\
\hline F & 0 & 0 & 3.79 & 4.36 & 0 & 0 & 0 & 0 & 0 \\
\hline G & 1.62 & 0 & 4.74 & 4.36 & 0 & 0 & 0 & 0 & 0 \\
\hline H & 4.86 & 0 & 4.74 & 4.36 & 0 & 0 & 0 & 0 & 0 \\
\hline
\end{tabular}

Table 3: Pollution loads at CSO chambers and storage tanks at $\mathrm{t}=15$ minutes.

\begin{tabular}{|c|c|c|c|c|c|c|c|c|c|}
\hline \multirow{2}{*}{ Solution } & \multicolumn{10}{|c|}{ Pollution loads (kt/day) } \\
\cline { 2 - 11 } & $T 1$ & $T 2$ & $T 3$ & $T 4$ & $T 5$ & $T 6$ & $T 7$ & $T 8$ & $T 9$ \\
\hline A & 0 & 0 & 0 & 0 & 0 & 0 & 0 & 0 & 0 \\
\hline B & 0 & 0 & 0 & 0.38 & 0 & 0 & 0 & 0 & 0 \\
\hline C & 0 & 0 & 0 & 0.66 & 0 & 0 & 0 & 0 & 0 \\
\hline D & 0 & 0 & 0 & 0.85 & 0 & 0 & 0 & 0 & 0 \\
\hline E & 0 & 0 & 0.26 & 0.85 & 0 & 0 & 0 & 0 & 0 \\
\hline F & 0 & 0 & 1.00 & 0.85 & 0 & 0 & 0 & 0 & 0 \\
\hline G & 0.27 & 0 & 1.25 & 0.85 & 0 & 0 & 0 & 0 & 0 \\
\hline H & 0.77 & 0 & 1.25 & 0.85 & 0 & 0 & 0 & 0 & 0 \\
\hline
\end{tabular}

Table 4: Wastewater depths at CSO chambers and storage tanks at $\mathrm{t}=15$ minutes.

\begin{tabular}{|c|c|c|c|c|c|c|c|c|c|}
\hline \multirow{2}{*}{ Solution } & \multicolumn{10}{|c|}{ Wastewater depths $(\mathrm{m})$} \\
\cline { 2 - 11 } & $T 1$ & $T 2$ & $T 3$ & $T 4$ & $T 5$ & $T 6$ & $T 7$ & $T 8$ & $T 9$ \\
\hline A & 5.37 & 0 & 7.87 & 8.01 & 0.02 & 7.18 & 7.63 & 6.47 & 7.84 \\
\hline B & 5.37 & 0 & 7.95 & 8.28 & 0.02 & 7.18 & 7.63 & 6.47 & 7.84 \\
\hline C & 5.40 & 0 & 7.93 & 8.38 & 0.02 & 7.18 & 7.63 & 6.47 & 7.84 \\
\hline D & 5.40 & 0 & 7.91 & 8.45 & 0.02 & 7.18 & 7.63 & 6.47 & 7.84 \\
\hline E & 5.40 & 0 & 8.10 & 8.45 & 0.02 & 7.18 & 7.63 & 6.47 & 7.84 \\
\hline F & 5.41 & 0 & 8.32 & 8.45 & 0.02 & 7.18 & 7.63 & 6.47 & 7.88 \\
\hline G & 5.63 & 0 & 8.39 & 8.45 & 0.02 & 7.18 & 7.62 & 6.53 & 7.80 \\
\hline H & 5.86 & 0 & 8.39 & 8.45 & 0.02 & 7.18 & 7.62 & 6.53 & 7.80 \\
\hline
\end{tabular}




\section{Conclusions}

Hydraulic simulation results show that the developed multi-objective optimization approach produces feasible solutions. The presented multi-objective optimization approach shows a considerable improvement in controlling urban wastewater systems compared to the previous work by the same authors. However, the proposed model gives the optimal CSO control settings where a single set of static control settings is used throughout the 15 minutes storm duration. Further research is requited in developing an extended period dynamic optimization procedure for the full duration of the storm. The discussed constraint handling approach and the obtained results will be used to develop the dynamic optimization approach.

\section{Acknowledgements}

Upaka Rathnayake's PhD is funded by the UK government through Overseas Research Students Award Scheme and the University of Strathclyde. The authors are grateful for the above mentioned financial support.

\section{References}

[1] Beraud, B., Mourad, M., Soyeux, E., Lemoine, C., \& Lovera, M., Optimisation of sewer networks hydraulic behaviour during wet weather: coupling genetic algorithms with two sewer networks modelling tools. NOVATECH 2010, Lyon, France, 2010.

[2] Cembrano, G., Quevedo, J., Salamero, M., Puig, V., Figueras, J. \& Marti, J., Optimal control of urban drainage systems. A case study. Control Engineering Practice, 12, pp. 1-9, 2004.

[3] Darsono, S. \& Labadie, J.W., Neural-optimal control algorithm for realtime regulation of in-line storage in combined sewer systems. Environmental Modelling \& Software, 22, pp. 1349-1361, 2007.

[4] Meirlaen, J., Assel, J.V. \& Vanroleghem, P.A., Real time control of the integrated urban wastewater system using simultaneously simulating surrogate models. Water Science \& Technology, 45(3), pp. 109-116, 2002.

[5] Rathnayake, U.S., \& Tanyimboh, T.T., Multi-objective optimization of urban wastewater systems, $10^{\text {th }}$ International conference on Hydroinfomatics (HIC2012), Hamburg, Germany, 14-18 July 2012. Paper submitted.

[6] Deb, K., Pratap, A., Agarwal, S., \& Meyarivan, T., A fast and elitist multiobjective genetic algorithm: NSGA-II. IEEE Transactions on Evolutionary Computation, 6(2), pp. 182-197, 2002.

[7] Mussati, M., Gernaey, K., Gani, R., \& Jorgesen, S.B., Performance analysis of a denitrifying wastewater treatment plant. Clean Techn Environ Policy, 4, pp. $171-182,2002$. 
[8] Rathnayake, U.S., \& Tanyimboh, T.T., Integrated optimal control of urban wastewater systems, IWA-WCE conference, Dublin, Republic of Ireland, 13-18 May 2012. Paper accepted.

[9] Hernandez-Sancho, F., \& Sala-Garrido, R., Cost modelling in wastewater treatment processes: An empirical analysis for Spain. Dangerous pollutants (xenobiotics) in urban water cycle, 4, pp. 219-226, 2008.

[10] Rossman, L.A., US EPA SWMM 5.0 User's Manual EPA/600/R-05/040, Water Supply and Water Resources Division, National Risk Management Research Laboratory, Cincinnati, 2009.

[11] Thomas, N.S., Optimal pollution control models for interceptor sewer systems, Department of Civil Engineering, University of Liverpool, UK, 2000.

[12] Duncan, P.H., Urban stormwater quality: a statistical overview, ReportCooperative Research Centre for Catchment Hydrology, 99/3, ISBN 1876006455, 1999.

[13] Li, L., Yin, C., He, Q., and Kong, L., First flush of storm runoff pollution from an urban catchment in China. Journal of Environmental Sciences, 19, pp. 295-299, 2007.

[14] Morris, G.M., Agg, A.R., Clifforde, I.T., Ridout, K.J., Singleton, P., Tyson, J.M., and Wilson, A., Urban Pollution Management Manual, $2^{\text {nd }}$ Edition, Foundation for Water Research, Allen House, Buckinghamshire, SL7 1FD, UK, 1998.

[15] Qin, H., Khu, S., and Yu, X., Spatial variations of storm runoff pollution and their correlation with land-use in a rapidly urbanizing catchment in China. Science of the total environment, 408, pp. 4613-4623, 2010.

[16] Yusop, Z., Tan, L.W., Ujang, Z., Mohamed, M. and Nasir, K.A., Runoff quality and pollution loading from a tropical urban catchment. Water Science and Technology, 52(9), pp. 125-132, 2005.

[17] Deb, K., and Agrawal, R.B., Simulated binary crossover for continuous search space, Complex Systems, 9, pp. 115-148, 1995. 